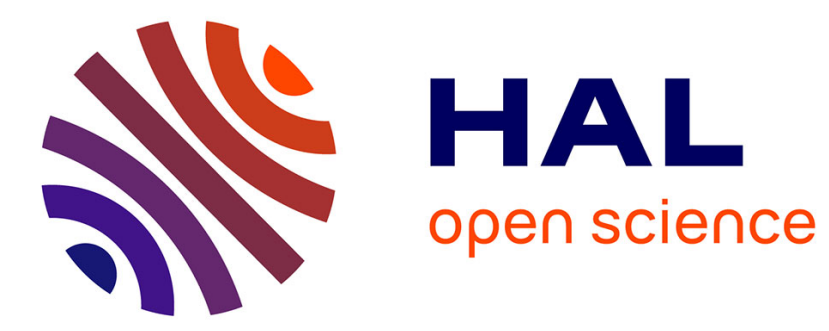

\title{
STUDY OF THE NEUTRON-PROTON WEAK INTERACTION AT THE ILL REACTOR
}

M. Avenier, G. Bagieu, J. Cavaignac, D. Koang, A. Idrissi, B. Vignon, R. P. Wilson

\section{- To cite this version:}

M. Avenier, G. Bagieu, J. Cavaignac, D. Koang, A. Idrissi, et al.. STUDY OF THE NEUTRONPROTON WEAK INTERACTION AT THE ILL REACTOR. Workshop on Reactor Based Fundamental Physics, 1983, Grenoble, France. pp.C3-99-C3-102, 10.1051/jphyscol:1984320 . jpa-00224034

\section{HAL Id: jpa-00224034 https://hal.science/jpa-00224034}

Submitted on 1 Jan 1984

HAL is a multi-disciplinary open access archive for the deposit and dissemination of scientific research documents, whether they are published or not. The documents may come from teaching and research institutions in France or abroad, or from public or private research centers.
L'archive ouverte pluridisciplinaire HAL, est destinée au dépôt et à la diffusion de documents scientifiques de niveau recherche, publiés ou non, émanant des établissements d'enseignement et de recherche français ou étrangers, des laboratoires publics ou privés. 


\title{
STUDY OF THE NEUTRON-PROTON WEAK INTERACTION AT THE ILL REACTOR
}

\author{
M. Avenier, G. Bagieu, J.F. Cavaignac, D.H. Koang, A. Idrissi, B. Vignon \\ and R. Wilson* \\ Institut des Sciences Nucléaires, 53, avenue des Martyrs, \\ 38026 Grenoble Cedex, France \\ ^Department of Physics, Harvard University, Cambridge, MA 02138, U.S.A
}

Résumé - L'appareil, construit par une collaboration ISN-Grenoble-Harvard, a été installé sur le faisceau du polariseur PN7 dans le but de détecter une corrélation $\sigma_{n} . k_{y}$ dans le système à deux nucléons $(n-p)$. Cette expérience doit être un test de la contribution des courants neutres faibles à l'interaction nucléon-nuclèon. La description et les performances de l'appareil, ainsi que les résultats des premiers tests sont donnés.

Abstract - We present a description of the ISN-Harvard apparator, installed on the PN7 polarizer for detecting the $\sigma_{n} . k_{\gamma}$ correlation in the two nucleon $(n-p)$ system. This experiment would be a crucial test on the weak neutral current contribution to the nucleon-nucleon weak interaction Performances and preliminary test results are given.

\section{Introduction}

The search for a parity violation in the NN system ( $n-p$ interaction) is based on the hypothesis of the universality of weak interaction (characterized by parity violation). The $\gamma$ ray asymmetry from the $\vec{n}+p \rightarrow d+\gamma$ reaction is only due to the $\Delta I=1$ isospin contribution of the weak $\mathbb{N N}$ interaction and more precisely to the $\pi$ meson exchange (one of the N-N-M vertex being assumed to be weak). It confers a particular interest on this experiment as it would be the best test (in the low energy domain) of the weak neutral force between hadrons. Due to the $\Delta S=0$ rule only the $N-N$ or $N-\bar{N}$ systems can receive a contribution from this force (exchange of the $Z^{\circ}$ intermediate vector boson of the Weinberg-Salam mode1).

The $\mathrm{N} \mathrm{N}$ interaction is understood as the superposition of the strong nuclear force (which is parity conserving) and the weak force (parity non-conserving) with the relative intensities 1 and $10^{-8}-10^{-9}$. It is very difficult to detect such effects and a low statistical precision is usually obtained

The estimation of the effect is

$$
|A| \simeq 5 \times 10^{-8}
$$

and the present experimental upper limit is

$$
\text { A }<2 \times 10^{-7} \text { ISN-Harvard } 1975 \text { (ref. 1). }
$$

The above estimation is based on the "best values" of the weak meson coupling constants given by Desplanques-Donoghue and Holstein (Ref. 2) and the description due to Desplanques - Missiner (ref. 3) of weak processes. 
Principle of the experiment

The capture of polarized neutron by a proton form a high energy oriented scattering state which decays with a $2.2 \mathrm{MeV} \gamma$ ray to the deuteron ground state.

$$
\begin{aligned}
& \mathrm{n}+\mathrm{p} \longrightarrow(\mathrm{n} \mathrm{p}) \longrightarrow \mathrm{d}+\gamma \\
& \left({ }^{3} \mathrm{~S}_{1}+{ }^{3} \tilde{\mathrm{P}}_{1}\right) \quad\left(\mathrm{M}_{1}+\tilde{\mathrm{E}}_{1}\right)
\end{aligned}
$$

Any parity impurity in this process has effects on the $\gamma$ ray characteristics, especially ${ }_{\sim}$ on its angular distribution through the interference of the regular $M_{1}$ and irregular $\widetilde{E}_{1}$ transitions giving rise to pseudoscalar quantities such as the $\gamma$ asynmetry coefficient $A_{\gamma}$ inquired here. The $\gamma$ angular distribution can be written as $(\vec{P}$ being the beam polarization ) :

$$
W \quad \alpha 1+A \cdot|\vec{P}| \cdot \cos (\vec{P}, \vec{k} \gamma)
$$

As the detection of a $\vec{P}$. $\vec{k} \gamma$ correlation is the aim of the experiment, the equivalence of parity conjugate systems ensures the equiprobability for processes with positive and negative correlations. Among the different experimental possibilities the best one is the most symmetrical set up. This could be achieved with two detectors of same quality for correlation detection at the same time (forward and backward detection relative to beam polarization). To compensate any difference, compared to an ideal geometry, we periodically invert the set up by two current sheets (spin flip) and also by reversing the magnetic fields applied along the beam path.

Thus any uncorrelated spin effects will be averaged over the different configurations and will cancel.

From the statistical point of wiew we need.

- A high nuclei density target : large size liquid parahydrogen target

- a high flux, low energy, high degree of polarization beam

- a set of high efficiency accurate detectors

The low energy beam fed from the PN7 apparatus $\left(\lambda^{*}=4.5 \mathrm{~A}^{\circ}\right)$ allows the scattering to be done on the whole molecule (without spin flip because parahydrogen has $J=0$ angular momentum) without transition to the ortho state $(\Delta E=14.7 \mathrm{~m} \mathrm{eV})$. Furthermore it ensure that the $n-p$ nuclei are in $S$ state (with relative angular momentum $1=0$ ) avoiding appearence of regular $\mathrm{P}$ states (with $1=1$ ) in agreement with parity conservation.

As the number of photon incidents upon each detector is of the order of $10^{9} / \mathrm{sec}$, only the mean value of this flux is suceptible to measurement (exactely the mean continuous voltage at the photomultipliers anode). Two digital voltmeters (ADC, 16 bits resolution) are used to convert these signals before analysis. We took a special care in the design and choice of electronic components to avoid contribution of drift and pick up signals.

\section{Performance of the apparatus}

The beam at the exit of polarizer has a polarization of $97 \%$ and a flux of $410^{8} \mathrm{n}$ $\mathrm{cm}^{-2} \mathrm{~s}^{-1}$ over a $15 \mathrm{~cm}^{2}$ cross section with a cut off wave-length of $4.5 \AA$ (ie En $=$ $4 \mathrm{meV}$ ). The efficiency of each spin flipper was measured to be of the order of $94:$

- The effective polarization of captured neutrons in the 351 target is estimated to be $92 \%$ of incident polarization due to the remaining ortho-hydrogen at $20 \mathrm{~K}$ thermal equilibrium $(0.2 \%)$. The probability for neutron to stop in hydrogen is of the order of $71 \%$ which correspond to a signal over noise ratio at least equal 8 . Each detector (400 1 of liquid scintillator NE 235) have an efficiency of about $17:$ (including solid angle) which correspond to the creation of more than 20 photo-electron per $\gamma$ and MeV. 
Validity of the experiment/ Preliminary tests

\section{- 60 Co_zero_test}

The distribution of capture photon being mainly symmetrical, we can simulate it with an unoriented radioactive source. This measurenent ckecks the quality of the set-up (sensitivity to drift, influence of magnetic fields on detection process...). But above all it is an absolute zero check of the apparatus in the sense that the source own fluctuations were negligible (which is not the case with the beam whose fluctuations are of the order of $1 \frac{\mathrm{o}}{\mathrm{o}}$ ).

This test was performed with a $114 \mathrm{mCi}{ }^{60} \mathrm{Co}$ source. The uncertainty of individual measurements is $\simeq 2.510^{-5} \mathrm{i}$ e about $610^{-8} /$ day, so that for a 40 days experiment we have measured

$$
A=(0.5 \pm 1.1) \times 10^{-3}
$$

- Empty target_zeroro test.

Here we carried out a measurement of background asymmetry (B4 C associated asymmetry). The accuracy to be obtained lies in the range of $10^{-7}$ to assert that any significative effect greater than $1 \times 10^{-8}$ is due to hydrogen (the signal to noise ratio being in this case is estimated to be $\sim 10$ ). For a total of $120 \mathrm{~h}$ runs we measured the asymmetry

$$
A=(9.7 \pm 12) \times 10^{-8}
$$

that is after correction for mean polarization and geometrical factor

$$
A=\left(9.7 \pm 15 \text { stat. } \pm 1_{\text {cal }}\right) \times 10^{-8}
$$

\section{- Calibration of the set up}

Very few experimental results exist for this mode of detection. We take advantage of an experiment of the same type performed by the Leningrad group on 35 chlorine (ref. 4) that is $A=(-27.8 \pm 4.9) \times 10^{-6}$

For that test we use a target of about $40 \mathrm{gr}$ of chemically pure Na $\mathrm{Cl}$ powder. Our measurement for a $12 \mathrm{~h}$ run gave the raw result

$$
\mathrm{A}(\mathrm{Na} \mathrm{Cl})=(-1.31 \pm 0.07) \times 10^{-5}
$$

that is after corrections

$$
\text { A }\left({ }^{35} \mathrm{C} 1\right)=\left(-21 \pm 1_{\text {stat }} \pm 2_{\mathrm{cal}}\right) 10^{-5}
$$

confirming the magnitude and the sign of the effect detected at Leningrad.

\section{- Natural}

The ${ }^{117} \mathrm{Sn}$ isotope is one of the nuclei which have been the most inquire upon weak nuclear interaction with many different technics and the effect is well proven and known. A direct measurement of natural tin associated effect was undertaken with a metallic target. We observed for a three days mun the raw asymmetry.

$$
A=(-1.91 \pm 0.95) \times 10^{-6}
$$

which correspond to the value.

$$
A=\left(-2.5 \pm 1.2 \text { stat } \pm 0.2_{\text {cal }}\right) \times 10^{-6}
$$

We would like to thank the staff of Institut Laue-Langevin, especially the EDEX departement, for their help. 


\section{References}

1) J.F. Cavaignac, B. Vignon, R. Wilson - Phys. Lett. 67B, (1977) 148

2) B. Desplanques, J.F. Donoghue B.R. Holstein - Ann. Phys. (N.Y.) 124 (1980) 449

3) B. Desplanques, J. Minimer - Nuc1. Phys. A300, (1978) 286 ; Phys. Lett. 84B (1979) 363.

4) V.A. Vesna et al - JETP Lett. $\underline{36}$ (1983) 209 